\title{
A Reforma agrária como elemento base para um relevante movimento territorial em Feira de Santana-Ba
}

\section{Agrarian reform as a basic element for a relevant territorial movement in Feira de Santana-Ba}

\author{
José Roberto Silva de Souza ${ }^{1 *} \bowtie$ (iD), José Raimundo de Oliveira Lima ${ }^{\natural} \bowtie$ (iD) \\ 1Departamento de Ciência Humanas e Filosofia, Universidade Estadual de Feira de Santana, \\ Feira de Santana, Bahia. \\ 2 Departamento de Ciências Sociais Aplicadas, Universidade Estadual de Feira de Santana, \\ Feira de Santana, Bahia. \\ E-mail: zeraimundo@uefs.br \\ *E-mail para correspondência: zerobertouefs@gmail.com
}

\author{
Recebido (Received): 24/08/2019 \\ Aceito (Accepted): 02/06/2020
}

\begin{abstract}
Resumo: O presente trabalho pretende analisar, à luz da necessidade da Reforma Agrária, a estruturação territorial das famílias camponesas acampadas em uma fazenda pertencente ao Estado da Bahia, no município de Feira de Santana. A propriedade nos idos da década de 1980 era utilizada por uma empresa pública conhecida pelo nome de Empresa Baiana de Desenvolvimento Rural (EBDA), como uma estação experimental, para desenvolvimento de assistência técnica, pesquisa e extensão agrícola. Utilizamos metodologicamente o estudo sobre teorias territoriais, bem como documentos que estão diretamente relacionados à propriedade, cuja dinâmica nos dará linhas gerais de abordagem. Por se tratar de uma pesquisa social, apresentamos dados da investigação desenvolvida no acampamento, por meio de entrevista semiestruturada aplicada aos acampados. Trata-se de uma área de terra onde está localizado um acampamento do Movimento dos Trabalhadores Rurais Sem Terra (MST), que tem o nome de Estrela Vive, nome dado em memória a um de seus mais representativos militantes. Essas pessoas reivindicam ao governo do Estado da Bahia o assentamento delas sobre a área, ao mesmo tempo em que constroem um território com características próprias do movimento social a que pertencem. Infere-se que o processo organizativo e político-educativo desses trabalhadores imprime a relevância de um movimento territorial que vive uma luta constante pela reprodução de sua existência.
\end{abstract}

Palavras-Chave: Movimento Social; Acampamento; Território; Reforma Agrária;

\begin{abstract}
The present work intends to analyze, in the light of the need for Agrarian Reform, the territorial structuring of peasant families camped on a farm belonging to the State of Bahia, in the municipality of Feira de Santana. The property in the 1980s was used by a public company known as the Bahian Rural Development Company (EBDA), as an experimental station, for the development of technical assistance, research and agricultural extension. We methodologically use the study on territorial theories, as well as documents that are directly related to property, whose dynamics will give us general lines of approach. As it is a social research, we present data from the investigation developed in the camp, through semi-structured interview applied to the campers. It is an area of land where a camp of the Landless Rural Workers Movement (MST) is located, which has the name of Estrela Vive, a name given in memory to one of its most representative militants. These people claim to the government of the State of Bahia to settle them over the area, while building a territory with characteristics specific to the social movement to which they belong. It is inferred that the organizational and political-educational process of these workers impresses the relevance of a territorial movement that lives a constant struggle for the reproduction of its existence.
\end{abstract}

Keywords: Social movement; Camp; Territory; Land reform. 


\section{Introdução}

Este trabalho é fruto de um projeto de pesquisa desenvolvido no Mestrado em Planejamento Territorial da Universidade Estadual de Feira de Santana, em uma ocupação do Movimento dos Trabalhadores Rurais Sem Terra - MST, localizada dentro de uma fazenda, atualmente, pertencente à Secretaria de Administração do Estado da Bahia - SAEB. O acampamento instalado na fazenda é conhecido pelo nome de Estrela Vive e enfrenta, atualmente, uma série de desafios em busca da transformação da área em um assentamento da Reforma Agrária.

Nesse contexto, os problemas enfrentados pelas famílias assentadas podem ser qualificados como uma luta territorial existente no âmbito do município de Feira de Santana e do Estado da Bahia, algo não comum, enquanto movimento territorial por reforma agrária, nessa região. Por conseguinte, pretendemos, por meio de sustentação teórica focada na área, discutir sobre a concepção de territórios e seus desdobramentos, analisando como o MST, em Feira de Santana, constrói esse movimento territorial.

Após a ocupação da fazenda, as famílias obtiveram um certo grau de domínio sobre a área, construindo e modelando o espaço de acordo com suas necessidades. Diante disso, apresentaremos dados obtidos através da pesquisa social, por intermédio da aplicação dos instrumentos metodológicos: entrevista semiestruturada e fichamento documental, que forneceram informações relacionadas à realidade das famílias do acampamento Estrela Vive.

Entendemos que a luta por reforma agrária é uma luta territorial, uma luta pela construção de um território ou luta por territorialização. Esse é o grande desafio deste trabalho, nos debruçarmos sobre os elementos da construção do território dos Sem Terra, pois acreditamos que fazem parte da luta cotidiana desses trabalhadores e trabalhadoras.

Diante o exposto, uma indagação se apresenta: como o MST, à luz da reforma agrária, se territorializa, em Feira de Santana, no espaço do acampamento Estrela Vive?

Para responder a essa questão, propomos como objetivo, analisar, diante da necessidade de uma Reforma Agrária, a construção territorial das famílias acampadas em uma fazenda pertencente ao Estado da Bahia no município de Feira de Santana.

Visando dar conta do objetivo central, elencamos os seguintes objetivos específicos: fazer revisão bibliográfica sobre território; apresentar elementos da localização geográfica e, por fim, analisar estruturas organizativas do acampamento Estrela Vive. Nessa esteira, esses objetivos se consubstanciarão nos principais eixos desta pesquisa.

Metodologicamente, a pesquisa tem sustentação teórica em referências das áreas de Ciências Humanas e da Filosofia, guiada por uma revisão bibliográfica, por análises de alguns documentos que demarcam elementos da territorialidade mencionada e por dados da entrevista semiestruturada aplicada no acampamento. Utilizamos, também, uma síntese sobre o estudo de teorias territoriais, bem como de documentos que estão diretamente relacionados à propriedade. Analisamos os dados da pesquisa desenvolvida no acampamento, por meio de uma entrevista semiestruturada aplicada com os acampados, lançando mão das observações sistemáticas dos pesquisadores, bem como da vivência realizada durante o período 2019/2020, naquele espaço, na perspectiva da pesquisa-ação conforme discute Thiolent (2011).

Com efeito, este artigo está estruturado, além da introdução e das considerações finais, dos seguintes eixos temáticos: 1.Sem Terras: O desafio de demarcar o território; 2. História do acampamento; 3. Localizando o Imóvel; 4. Percepção da situação jurídica; 5. Como o MST constrói seu território.

\subsection{Sem terras: o desafio de demarcar o território}

Nosso desafio, neste primeiro tópico, está em compreender a territorialidade da questão agrária enfrentada pelas famílias do MST em Feira de Santana. Para isso, precisaremos, dentre outras coisas, conceituar território, nos posicionando sobre o assunto, e analisar o conceito e tipologias territoriais encontradas em nossa rica literatura.

Podemos assim, inicialmente, trazer as lições que tratam o território como um fragmento do espaço geográfico, ou seja, um lugar físico e aberto para as ações humanas. Sendo um espaço contínuo, porém dividido, limitado, por mais que esteja em pleno crescimento, onde há transformações diversas e constituído de forma organizada. Assim, conforme Gottmann (2012), o território é fruto de repartição e de organização.

Nessa afirmação, já podemos identificar alguns elementos que se tornam nosso objeto de estudo: um território - a porção do espaço geográfico - a fazenda, onde são realizadas diversas atividades humanas; se 
trata de um espaço contínuo, no entanto, repartido. As famílias se organizam para garantir o acesso à terra a todos ali presentes. Dessa forma, podemos afirmar que o acampamento Estrela Vive é um território, tendo em vista que possui todos os elementos indicados na definição engendrada por Gottmann. (GOTTMANN, 2012).

No entanto, só esse conceito não é capaz de significar por inteiro o que é território. Temos outros elementos que nos ajudam a compreender melhor esse termo. Assim, outra definição dialoga com o conceito aqui apresentado, segundo a qual território é uma concepção comunitária de múltiplas dimensões, múltiplas territorialidades, diferenciando o território do espaço geográfico, a partir de três atributos primordiais, quais sejam, as relações de poder, as redes e as identidades. Nesse sentido, são processos espaço-temporais que marcam determinadas parcelas do espaço, nas formas área-rede, rede-rede ou área-rede-lugar. (SAQUET 2009).

Ao adentrarmos no acampamento, podemos perceber que se trata de uma construção coletiva e multidimensional, tendo em vista que ali se encontram diversos elementos que o caracterizam como variadas territorialidades, ou seja, cada um desses elementos apresenta elementos peculiares ao território.

As famílias lutam por terra, mas não apenas isso, elas também querem educação para seus filhos, saúde para o conjunto da comunidade, produção de alimentos saudáveis na terra ocupada - isso tudo já faz do acampamento um território coletivo e multidimensional, tendo em vista que "o homem age no espaço (natural e social) de seu habitar, produzir, viver, objetiva e subjetivamente" (SAQUET, 2009, p.81).

Em um esforço para diferenciar o espaço de território, apontando alguns processos que oferecem base para essa distinção, Saquet (2009) aponta as relações de poder num entendimento multidimensional, criando campos de força econômicos, políticos e culturais imateriais; considera também a construção histórica e relacional das identidades e, por fim, a dinâmica de territorialização, desterritorialização e reterritorialização, aprimorado ao jeito de cada um. (SAQUET, 2009).

Tendo por referência o conjunto do acampamento Estrela Vive, podemos afirmar que nesse espaço estão presentes os processos que são base dessa territorialização. As relações de poder que envolvem aquela realidade estão voltadas para os entes federados que administram os conflitos agrários - Estado, União e Município - envolvidos nessa relação. Na mesma esteira, temos o poder judiciário, onde o enfrentamento é ainda mais acirrado. Essas relações caracterizam o princípio da "multiescalaridade" do território, reconhecendo assim os diversos territórios existentes. (FERNANDES, 2008, p. 280).

O MST é um movimento de trabalhadores, fruto da concentração de terras no Brasil, caracterizado como um problema histórico. Assim, o latifúndio é a grande razão da existência do MST. Geralmente, um acampado tem, em sua família, alguém que um dia teve terra, de alguma forma, dela foi expulso, e tenta retornar a sua raiz camponesa, realizando o complexo movimento da territorialização, desterritorialização e reterritorialização.

Com efeito, estamos de acordo com Saquet (2009) quando afirma que essa "tal diferenciação é necessária, porém é fundamental reconhecer que espaço e território não estão separados: um está no outro". (SAQUET, 2009, p. 83).

Assim, para sintetizarmos ainda sobre a definição de território, afirmamos que a territorialidade é sinônimo das ações humanas na tentativa de controle em que se influencia ou afeta objetos, pessoas e relações numa área delimitada (SAQUET, 2009), no nosso caso, no espaço do assentamento. Portanto, as questões enfrentadas pelo acampamento é uma das dimensões do território, pois se trata da tentativa de controlar o acesso e a posse da terra.

Dentre outros tantos problemas que poderíamos encontrar em um acampamento do MST, que é uma demonstração de múltiplos territórios, existem questões dentro do nosso "território" que exigem uma análise atenciosa, numa perspectiva de apontar soluções para tamanho imbróglio.

Partindo da concepção de que o território é multidimensional, compreendemos que suas dimensões são concebidas pelas práticas sociais dos sujeitos na relação com a natureza e entre seus pares. Assim, a multiplicidade dimensional é produzida no âmbito das relações sociais, econômicas, políticas, ambientais e culturais. Dessa forma, segundo Fernandes (2008), é por meio das ações e das intencionalidades que se constroem o espaço e suas relações. Destarte, podemos afirmar que o território organizado pelo MST, criado com a intencionalidade de ver a terra repartida, é multidimensional, como poderemos analisar no decorrer deste trabalho. 
Fernandes nos alerta que tipologia de territórios e a multiterritorialidade são objetos distintos. O segundo nasce do primeiro, sendo as territorialidades representações dos tipos de uso dos territórios. (FERNANDES, 2009).

Tendo discutido a complexidade pela qual um território é caracterizado, conhecidas as mais diversas teorias que a apresentam, conceituam e tipificam, analisaremos agora, dentro da multidimensionalidade do território, o território de luta pela terra das famílias do MST, em Feira de Santana.

\section{História do acampamento}

As lideranças do MST, Coordenação e Direção, procuram os líderes dos bairros, nas cidades da região, propondo que reúnam os moradores, com o objetivo de discutir a necessidade de lutar pela reforma agrária. Essa reunião só é possível quando as lideranças dos bairros expressam certa simpatia pela luta agrária, caso contrário, o bairro que seria alvo das reuniões ficaria de fora.

Após a programação das reuniões, os representantes do MST comparecem na data e no horário previstos para dar início a esse diálogo. Essa reunião é apenas uma das muitas que ocorrerão. Não é um processo curto, exige a programação de outros encontros, uma vez que não é possível abordar todo diálogo necessário para mobilizar as famílias interessadas em um único momento.

A pauta dessas reuniões refere-se, principalmente, a assuntos relacionados à Reforma Agrária, mais especificamente, no que tange a seus aspectos jurídicos, numa tentativa de demonstrar que se trata de um direito da classe trabalhadora. No entanto, não são apenas essas questões que são tratadas, é necessário também dialogar sobre o que cada família ou indivíduo deve contribuir para montar o acampamento. Dentre as necessidades mais emergentes estão a doação de ferramentas como machado, foice, facão e enxada, além de lona preta que é um símbolo da luta pela terra no MST. Deve-se pensar também na alimentação para passar pelo menos 15 dias no acampamento. $\mathrm{O}$ transporte é uma preocupação imediata, pois é preciso fretar carros para as famílias que não tiverem transporte próprio.

Antes de ir para ocupação, há uma última reunião no bairro para perceber como as famílias estão, se prepararam tudo que será necessário e, ainda, para marcar a data, horário e local de partida da cidade. Esse local de partida costuma ser em alguma estrada ou caminho que dá acesso ao imóvel que será ocupado - local onde as famílias de todos os bairros se reuniram durante a fase de planejamento. É costumeiro também ocorrer esse encontro no local de partida, durante as madrugadas.

A ocupação da Fazenda Cruzeiro do Mocó se deu assim, durante uma madrugada. Um militante pertencente à coordenação do MST, conhecido pelo apelido de "Estrela", foi um dos organizadores da ocupação. É certo que houve outras pessoas contribuindo nesse processo, no entanto, ele foi uma das pessoas que marcou a vida das famílias. Infelizmente, após liderar esse processo de ocupação, acabou falecendo. Ele foi homenageado pelas famílias que batizaram o acampamento com o seu apelido "Estrela".

Atualmente, mais de 11 anos depois, ficaram poucas pessoas que naquela madrugada do dia 16 de março de 2009 ocuparam a propriedade. Muitas desistiram e outras tantas foram assentadas em terras que foram destinadas para assentamento. Vale lembrar que não é só por meio desse processo de mobilização que as famílias conseguem fazer parte do acampamento.

Após a ocupação, depois que as primeiras famílias chegam, se inicia um novo processo de mobilização, mas dessa vez, de forma diferenciada. Os acampados, geralmente, percebendo que é um ambiente seguro, convocam parentes, familiares, vizinhos para virem para o acampamento, pois todos e todas ali são solidários enquanto companheiros de movimento.

Há casos de pessoas que ficam sabendo da existência do acampamento pelos meios de comunicação e vão até lá para saberem se podem acampar. Caso haja autorização, eles passam a compor o movimento.

\section{Localizando o imóvel}

Entre as dificuldades do território, uma delas se refere à localização da fazenda, haja vista que o município de Feira de Santana, nos âmbitos do Legislativo e Executivo, está articulando um processo de expansão urbana da cidade, podendo dessa forma, atingir a fazenda que é objeto da nossa pesquisa.

A área do município de Feira de Santana foi expandida pela Lei 075/2013, que determinou o acréscimo do território urbano, avançando sob a zona rural, concebendo assim outros bairros, como se pode verificar nos artigos $3^{\circ}$ e $4^{\circ}$ da Lei complementar $\mathrm{n}^{\circ} 75$, de 20 de junho de 2013, que fixa os limites interdistritais, 
ampliando o perímetro urbano de Feira de Santana, delimitando seis novos bairros, a saber: Vale do Jacuípe; Pedra Ferrada; Cis Norte; Mantiba; Registro e Chaparral.

A proposta emprega um dispositivo denominado macrozoneamento, que se define no Art. 180 do Projeto do Plano Diretor de Desenvolvimento Urbano e Territorial de Feira de Santana (2018), como um instrumento que delineia a estruturação e divisão territorial, urbano e rural, diante das ações estratégicas de desenvolvimento urbano, rural e socioeconômico previstas no mesmo documento.

Por esse motivo, se concebeu uma sequência de novos lugares no município, ampliando a Macroárea de Expansão Urbana, que no Art. 194 do Plano Diretor (1998) - a define como como espaço territorial de ampliação do tecido urbano da cidade de Feira de Santana, que se caracteriza como um avanço da malha urbana, prioritariamente para os sentidos nordeste e sudeste do território. Essa ampliação avança pela zona rural da sede, atingindo os limites do município, na margem direita do rio Pojuca, e, como segundo vetor de expansão, segue pelo lado oeste, continuando pelo Vale do Jacuípe, nas cercanias do condomínio Alphaville.

Nesta Macroárea, com efeito, onde estão traçados os bairros criados pela Lei 075/2013, o acampamento faz limites com um dos bairros gerados pela Macroárea, o Vale do Jacuípe, onde encontramos uma baliza entre urbano e rural.

Como o imóvel foi atingido pela expansão urbana, temos mais um conflito territorial que alcança a esfera jurídica em diversas dimensões, haja vista, a transformação da área rural em urbana, atingindo direitos como o previdenciário, que trata da aposentadoria rural, por exemplo, além de dificultar ainda mais a possibilidade de se criar um assentamento rural dentro do território urbano expandido.

No mapa abaixo (Figura 1), é possível ver a localização do acampamento, através de mapa geoprocessado, situado dentro do município de Feira de Santana.

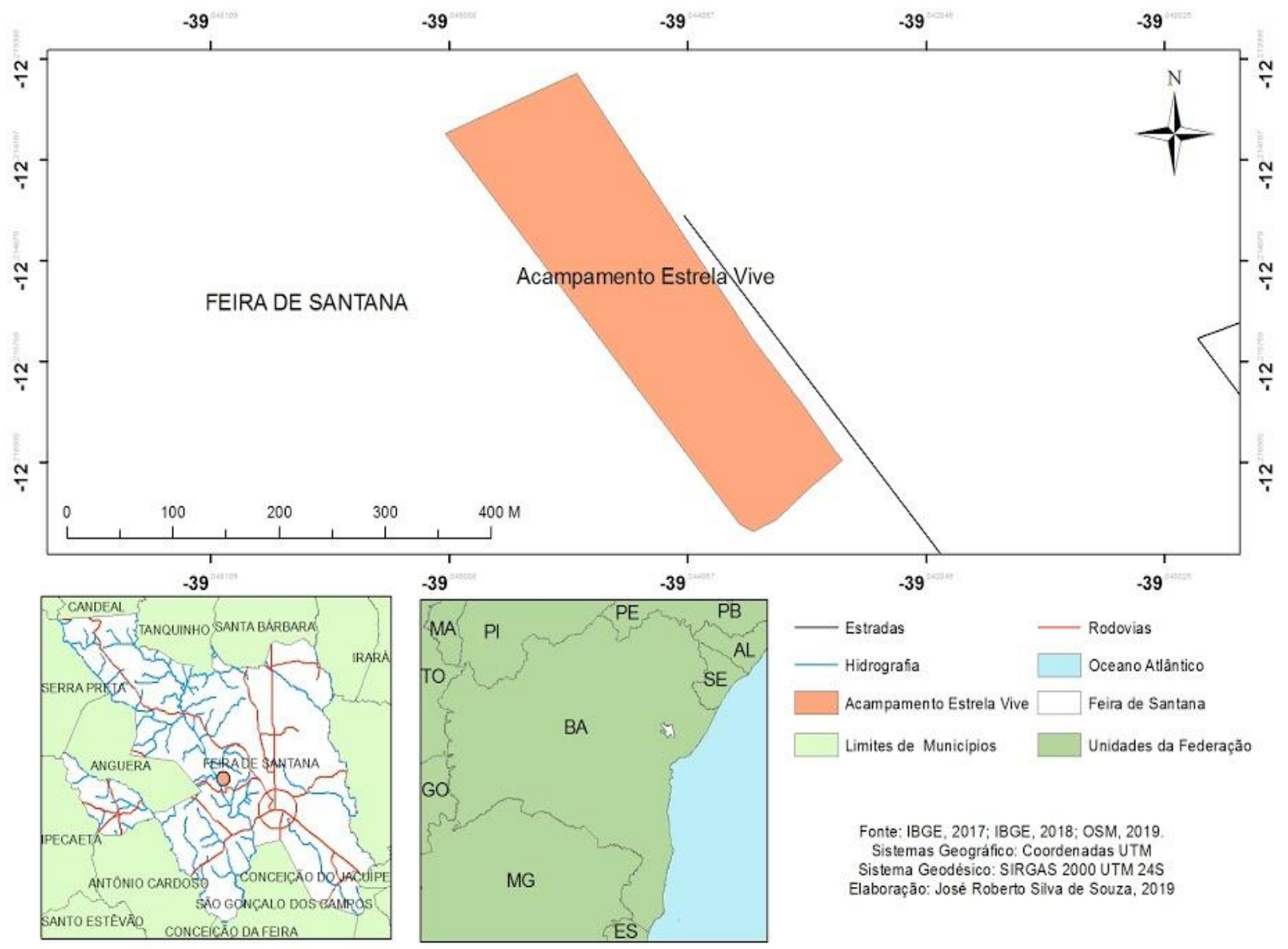

Figura 1: Localização do Acampamento Estrela Vive. Fonte: Criação do autor, agosto/2019.

A Empresa Baiana de Desenvolvimento Rural (EBDA) fora criada para prestar serviços de assistência técnica, extensão rural e pesquisa agropecuária no Estado da Bahia e foi extinta pelo decreto ${ }^{\circ} 17.037$ de 23 de setembro de 2016. Ela chegou a atuar em 417 municípios baianos, atendendo, em média, 316.000 (trezentos e dezesseis mil) agricultores em toda Bahia. 
A dissolução da empresa foi deferida pela Lei 13.204 de 11 de dezembro de 2014, que determinou, através do artigo 35, a execução dos atos necessários à sua extinção.

Diversas famílias dispostas a ocuparem a área, provenientes de bairros da cidade de Feira de Santana, ocupam o imóvel localizado neste município, mantendo o sonho de serem assentados, e assim, lidar com a terra, gerar a produção e reprodução das suas existências.

\section{Percepção da situação jurídica}

Conforme apontaram as entrevistas semiestruturadas, as famílias têm clareza de que a fazenda é um bem público que pertence ao estado da Bahia e, por isso, toda a pauta de reivindicação é tratada com o governo da Bahia e com a secretaria da administração que são responsáveis pelo imóvel e pelas políticas agrárias do estado.

De acordo com o registro de imóvel anexado aos autos do processo judicial movido contra as famílias acampadas na fazenda, esta área foi formada a partir da compra de 4 imóveis, pelo Estado, sendo as duas primeiras aquisições efetuadas no ano de 1938 e duas outras em 1948. Diga-se de passagem, que se trata de um período governado por Getúlio Vargas que ficou conhecido por "Estado Novo".

Existe na justiça estadual, uma ação de despejo desde de 2009, em que o juiz julgou procedente o pedido e concedeu a liminar. Entretanto, a liminar nunca foi executada, tendo em vista as manifestações da polícia militar acostadas aos autos do processo, alegando que não tem contingente suficiente de policiais para promover o despejo das famílias.

Há, segundo o levantamento da pesquisa, uma promessa antiga do governo do estado que, ao dialogar com o movimento, expressa que não assentaria as famílias naquela área, mas que compraria uma outra propriedade para abrigá-las. No entanto, onze anos se passaram e as famílias permanecem na mesma fazenda, sem nenhuma ação administrativa por parte das autoridades públicas no sentido de tornar aquela fazenda em um assentamento.

Questionados sobre o que achavam da ocupação da fazenda, se era uma ação legal ou ilegal, as afirmações foram no sentido de que não há ilegalidade em ocupar um bem que não cumpre sua função social e, na opinião deles, ilegal é quando não se cumpre a lei. Percebe-se que eles demonstraram algum conhecimento sobre as leis brasileiras que regem a propriedade no Brasil, principalmente, a Constituição Federal que trata da reforma agrária.

Quando questionados sobre para onde iriam caso houvesse a execução do despejo determinado pela justiça, alguns responderam que voltariam para suas casas, outros disseram que permaneceriam no local para onde fossem transferidos. Muitos não têm casa e, muito menos, recursos para pagar aluguel. Assim, não resta outra alternativa a não ser permanecerem no acampamento.

As relações públicas com os mais diversos representantes da sociedade civil são uma estratégia de luta e de apoio do MST. As lideranças do acampamento têm contato permanente com os partidos de esquerda, com as associações comunitárias, com entidades sindicais das mais diversas representações de trabalhadores desde rural a sindicatos do comércio, indústria e petróleo. Relacionam-se também com as escolas e universidades públicas e, no caso específico, com a Universidade Estadual de Feira de Santana. Ou seja, não é uma luta solitária, diversos setores da sociedade apoiam a luta pela reforma agrária e, todos e todas têm consciência disso, não só do acampamento Estrela Vive.

\section{Como o MST constrói seu território - organização política}

Tendo como base os dados levantados pelo desenvolvimento da pesquisa, apresentamos na sequência, alguns elementos que demonstram a estruturação do território pelas famílias.

Uma vez ocupado o espaço, as famílias organizarão formas de se apossarem da área, adaptando-a às suas necessidades. As famílias são orientadas a participar das mais diversas atividades que irão ocorrer com base na dinâmica do movimento da ocupação. Entre essas atividades, estão aquelas pertencentes ao corpo organizativo do MST, as atividades de núcleo de família, setores e coordenação, que passaremos a expor a seguir.

O núcleo de família representa uma das principais peças organizativas do acampamento e é, a partir dele, que surgirão as demais tarefas e atividades delegadas no interior do acampamento. É no núcleo de família que se reúne todo acampamento caracterizados da seguinte forma: de 11 a 20 pessoas por núcleo; 09 setores por núcleo; e 02 pessoas para coordenação do acampamento por núcleo. 
O acampamento Estrela Vive tem 10 núcleos, contendo de 11 a 20 pessoas cada, esses 10 núcleos têm um calendário de reuniões programadas conforme a necessidade do grupo. Cada pessoa do grupo deve participar de um setor, e duas pessoas, um homem e uma mulher, devem fazer parte da coordenação.

Cada um dos 09 setores existentes, conforme o Tabela 1, tem uma tarefa objetiva no acampamento, para serem realizadas conforme orientação de quem os representa. Referem-se a setores de saúde, educação, juventude, gênero, disciplina, produção, comunicação, formação e trabalho. Cada setor é representado por uma ou duas pessoas.

Tabela 1: Organização Política

\begin{tabular}{ccc}
\hline Núcleo de Famílias & 10 em todo acampamento & 11 pessoas por núcleo \\
Coordenação & 20 pessoas no acampamento & 2 pessoas por núcleo \\
Setores & 90 pessoas no acampamento & 9 pessoas por núcleo \\
\hline
\end{tabular}

Fonte: Criação do autor, março/2020.

A coordenação será sempre representada por duas pessoas do núcleo, obrigatoriamente necessário que seja um homem e uma mulher, por se considerar a instância de representação com maior poder de decisão interna, garantindo, dessa forma, maior participação política das mulheres internamente.

Apesar de serem instâncias representativas, qualquer decisão tomada pelo acampamento é feita de forma coletiva, uma vez que a estrutura organizativa do núcleo de família possibilita a interação entre as famílias de todo o acampamento.

\subsection{Produção agrícola no território dos Sem Terra}

O plantio de alimentos e a criação de animais são elementos que brotam do território construído pelos Sem Terra, característica fundamental dos camponeses. A forma como se produz e se comercializa essa produção foi representada nos dados e nas informações obtidas na pesquisa.

Em primeira mão, haja vista a importância da produção de alimentos para o próprio consumo, há uma diversidade grande de alimentos que são gerados no acampamento como milho, feijão carioquinha e andu; hortaliças como alface, couve, coentro e cebolinha verde; frutas como umbu, laranja, banana, cajá, caju, manga, tamarindo, coco, melancia e seriguela; raízes como aipim, batata doce e legumes como tomate, abóbora, maxixe e caxixe.

Os animais também têm seu espaço para reprodução no interior do imóvel. São gado bovino, ovelhas, cabras, porcos, galinhas, cavalos, jumentos e burros, alguns para comercialização, outros para consumo próprio e para utilização no trabalho.

Até aqui, demonstramos o que se produz no acampamento. A pesquisa apresentou também dados da forma como se produz e todos afirmaram que têm preferência pelo cultivo de alimentos sem a utilização de agrotóxicos e sem insumos químicos, pois pretendem, dessa forma, preservar a saúde dos acampados e dos que consomem os alimentos produzidos.

O conjunto do imóvel rural ocupado está dividido em duas partes, de um lado, menos da metade da propriedade, fora determinado que apenas se plantassem vegetais, deixando a outra parte para criação de animais de médio e de grande porte, como bovinos e caprinos.

Tabela 2: Produção

\begin{tabular}{|c|c|c|c|}
\hline & Orgânico & Sem uso de agrotóxico & Sem uso de adubos químicos \\
\hline $\begin{array}{l}\text { Manejo do } \\
\text { solo }\end{array}$ & $\begin{array}{l}\text { Com tecnologia própria ou } \\
\text { com auxílio de programas e } \\
\text { projetos advindos da } \\
\text { universidade. }\end{array}$ & $\begin{array}{l}\text { Com tecnologia própria ou } \\
\text { com auxílio de programas e } \\
\text { projetos advindos da } \\
\text { universidade. }\end{array}$ & $\begin{array}{l}\text { Com tecnologia própria ou com } \\
\text { auxílio de programas e projetos } \\
\text { advindos da universidade. }\end{array}$ \\
\hline
\end{tabular}

Fonte: Criação do autor, abril/2020.

Toda essa produção é comercializada de diversas maneiras pelos acampados. Cada um opta pela forma como lhe convém comercializar de acordo com sua especificidade, apesar de existirem formas mais coletivas de vender os produtos da roça. 
Alguns compradores vêm até ao acampamento para adquirir alimentos na residência do acampado. Outros levam essa produção para a cidade de Feira de Santana para venderem nas ruas ou praças. Há também produtores que procuram o Centro de Abastecimento, quitandas e pequenos supermercados do município para ali venderem suas mercadorias.

E ainda se utiliza, como forma de comercialização, as feiras e os eventos realizados pelo MST tanto no Estado da Bahia, quanto em outros Estados do Brasil. Nesses eventos, o movimento MST garante toda a logística necessária para a realização e participação dos grupos.

\subsection{Representação por personalidade jurídica}

A representação por personalidade jurídica é mais um dos elementos que constituem a territorialidade Sem Terra. Há, no acampamento, uma pessoa jurídica que tem a função de representar essa comunidade em eventos que necessitam da sua presença, tais como em apresentação de projetos e solicitações junto às instituições estatais e da sociedade civil.

Trata-se de uma associação que representa os mais diversos interesses de seus associados moradores do acampamento, seja esse interesse econômico, produtivo, cultural, formativo, etc. Criada em 2018, recebeu o nome de Associação Rural Comunitária Estrela Vive (ARCEV).

A ARCEV é uma sociedade civil de responsabilidade limitada, sem fins lucrativos, com matriz situada dentro da área ocupada, podendo ser filiada toda pessoa que lá reside, não tendo um limite na quantidade máxima de associados.

Por meio da ficha documental, observamos que associação traz em seu estatuto algumas finalidades, como a proteção do meio ambiente, qualificação dos filiados capacitando-os para produção de alimentos saudáveis e dentro de um padrão de preservação ambiental. Além disso, prevê a contratação de assistência técnica e representação do acampamento diante dos poderes públicos de qualquer esfera, seja municipal, estadual ou federal.

Os associados possuem diversos direitos e deveres, como participar das discussões em assembleias e reuniões convocadas; solicitar informações sobre as atividades da ARCEV; consultar livros e documentos; participar de todas as atividades promovidas pela ARCEV; gozar das vantagens e benefícios que esta conceder aos filiados.

A associação apresenta uma estrutura administrativa necessária para sua existência composta por uma Assembleia Geral, Direção Executiva e o Conselho Fiscal - todos órgãos organizativos compostos por pessoas que foram eleitas para cada um dos cargos.

Tabela 3: Direitos e deveres dos Associados - ARCEV

\begin{tabular}{ccc}
\hline $\begin{array}{c}\text { Participar das } \\
\text { discussões }\end{array}$ & $\begin{array}{c}\text { Nas assembleias e reuniões } \\
\text { convocadas. }\end{array}$ & $\begin{array}{c}\text { Processo educativo e político que faz do associado } \\
\text { sujeito pleno. }\end{array}$ \\
Solicitar informações & $\begin{array}{c}\text { Sobre as atividades da ARCEV e } \\
\text { consultar livros e documentos. } \\
\text { Qualquer evento promovido pela } \\
\begin{array}{c}\text { Participar de todas as } \\
\text { atividades }\end{array}\end{array}$ & $\begin{array}{c}\text { Conhecer o processo educativo e político, bem } \\
\text { como criar e evoluir no movimento. }\end{array}$ \\
$\begin{array}{c}\text { Gozar das vantagens e } \\
\text { benefícios }\end{array}$ & $\begin{array}{c}\text { Concedidos pela ARCEV a seus } \\
\text { filiados. }\end{array}$ & $\begin{array}{c}\text { Valorizar e consolidar o associativismo como base } \\
\text { organizativo. } \\
\text { do movimento. }\end{array}$ \\
\hline
\end{tabular}

Fonte: Criação do autor, abril/2020.

\subsection{Mutirão - trabalho coletivo na comunidade}

Além de serem representadas por uma associação, as famílias ainda se organizam para executarem trabalhos que necessitam de grande força de trabalho. Todas as terças-feiras, as famílias se reúnem na sede da associação para determinarem a execução de alguma tarefa necessária no interior do acampamento.

Eles constroem casas, arrumam cercas, roçam as beiras da estrada de acesso ao acampamento, limpam os mais diversos açudes de contenção de água da chuva para utilização dos animais, contribuem, ajudam, orientam ou acompanham aqueles que se encontram com a saúde abalada, limpando seus quintais e roças, dentre outras tarefas que possam surgir. 
Considerando a existência de diversas estruturas físicas deixadas pela EBDA, como casas, galpões, currais e apriscos, este grupo também atua no sentido de manter preservadas e limpas essas estruturas.

Nessa esteira, está entre as tarefas desse coletivo, preparar o solo, efetuar o plantio de lavouras e cuidar delas, colher os frutos e ainda comercializar a produção das lavouras pertencentes à associação, uma vez que todo o recurso arrecadado por esse meio será investido nas necessidades da associação e também dos associados.

\section{Considerações finais}

A organização política do acampamento é a base principal para a territorialização dos Sem Terra. Uma vez estabelecido o modelo de representatividade, todas as ações encaminhadas dentro do acampamento serão realizadas de forma coletiva, tendo isso como princípio que reforça todas as práticas comunitárias.

Compreendemos que o acampamento Estrela Vive é um local marcado pela luta territorial em suas diversas dimensões, uma vez que ali estão presentes relações de natureza social, econômica, política, ambiental e cultural, bem como de diversas outras dimensões da vida.

A ocupação da Estação Experimental tem se mostrado necessária para chamar a atenção da sociedade para questão agrária do município, uma vez que se trata de uma área de terra pública em desuso pelo Estado e sem qualquer fim social.

Infere-se, com efeito, que reconhecer as dimensões territoriais do acampamento é importante para uma melhor compreensão dessa luta, pois dentro da complexidade social e inserido em uma realidade objetiva, é possível perceber, com precisão, a conflitualidade em torno do espaço existente.

A pessoa jurídica ali existente, ao mesmo tempo em que representa os interesses das famílias, traz para o território maior segurança, uma vez que cuida das questões mais burocráticas, administrativas, junto aos entes públicos municipal, estadual e federal, garantindo ao movimento um processo de valor político consolidado.

O trabalho coletivo demonstra uma forma de construção ou territorialização de um espaço onde a solidariedade entre as famílias prevalece. Infere-se a objetividade na busca de valorização da relação comunitária, característica fundamental das ocupações do MST e de muitas comunidades rurais, sendo assim elementos efetivos presentes neste território.

Portanto e, por fim, se observa que a forma como o movimento maneja a terra também é uma característica dos Sem Terra em produzir alimentos saudáveis, sem uso de agrotóxicos e insumos químicos. Essa tem sido a prática orientada e realizada permanentemente, cuja experiência aponta a reforma agrária como elemento base e relevante que justifica a existência de um movimento territorial diferenciado em Feira de Santana-Ba.

\section{Referências}

BAHIA. Lei $n^{\circ} 13.204$ de 11 de Dezembro de 2014. Modifica a Estrutura Organizativa da Administração Pública do Executivo Estadual e da das Outras Providências. Disponível em: http://leisestaduais.com.br/ba/lei-ordinaria-n-13204-2014-bahia-modifica-a-estrutura-organizacional-daadministracao-publica-do-poder-executivo-estadual-e-da-outras-providencias. Acesso em: 30/01/2019.

FEIRA DE SANTANA, Lei complementar $n^{\circ} 75$, de 20 de junho de 2013. Fixa os limites interdistritais, amplia o perímetro urbano e delimita 06 (seis) novos bairros do distrito sede do município de Feira de Santana e dá outras providências. Disponível em: https://leismunicipais.com.br/a/ba/f/feira-de-santana/lei complementar/2013/8/75/lei. Acesso em: 30/01/2019.

FEIRA DE SANTANA. Projeto de Lei do Plano Diretor de Desenvolvimento Urbano e Territorial de Feira de Santana. Abril de 2018. Disponível em: http://feiradesantana.ba.leg.br/wpcontent/uploads/2018/08/Plco20180003-PDDU.pdf. Acesso em: 30/01/2019.

FERNANDES, B. M. Entrando nos territórios do território. In: PAULINO, E. T.; FABRINI, J. E. (Org.). Campesinato e Território em Disputa. 1ª Edição.São Paulo: Expressão Popular, 2008. 
FERNANDES, B. M. Sobre a tipologia de territórios. In: SAQUET, Marcos Aurélio; SPOSITO, Elizeu Savério (Org.). Território e Territorialidades: Teoria, Processos e Conflitos. São Paulo: Expressão Popular, 2009. p. 197-215.

GOTTMANN, J. A evolução do conceito de território. Boletim Campineiro de Geografia, V.2, N.3, 2012. Disponível em: http://agbcampinas.com.br/bcg/index.php/boletimcampineiro/issue/view/v.\%202\%2C\%20n.\%203\%2C\%202012. Acesso em: 25 de outubro de 2019.

SAQUET, M. A. Por uma abordagem territorial. In: (Org.). Território e Territorialidades: Teoria Processos e Conflitos. São Paulo: Editora Expressão Popular, 2009. p. 73-94.

THIOLLENT, M. Metodologia da pesquisa-ação. 18 ed. São Paulo: Cortez, 2011. 